\title{
Role of brassinosteroids in rice spikelet differentiation and degeneration under soil-drying during panicle development
}

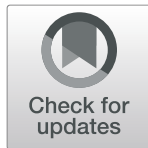

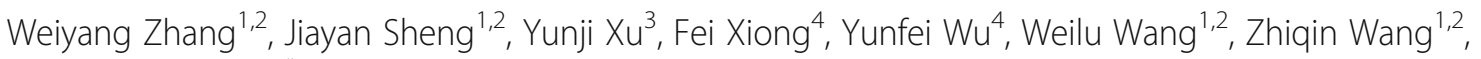
Jianchang Yang ${ }^{1,2,3^{*}}$ (D) and Jianhua Zhang ${ }^{5}$

\begin{abstract}
Background: Brassinosteroids (BRs) are a new group of plant hormones and play important roles in plant growth and development. However, little information is available if BRs could regulate spikelet development in rice (Oryza sativa L.) especially under soil-drying conditions. This study investigated whether and how BRs mediate the effect of soil-drying on spikelet differentiation and degeneration in rice. A rice cultivar was field-grown and exposed to three soil moisture treatments during panicle development, that is, well-watered (WW), moderate soil-drying (MD) and severe soil-drying (SD).

Results: Compared with the WW treatment, the MD treatment enhanced BRs biosynthesis in young panicles, increased spikelet differentiation and reduced spikelet degeneration. The SD treatment had the opposite effects. Changes in expression levels of key rice inflorescence development genes (OsAPO2 and OsTAW1), ascorbic acid (AsA) content, and activities of enzymes involved AsA synthesis and recycle, and amount of nonstructural carbohydrates (NSC) in young panicles were consistent with those in BRs levels, whereas hydrogen peroxide $\left(\mathrm{H}_{2} \mathrm{O}_{2}\right)$ content showed opposite trend. Knockdown of the BRs synthesis gene OsD11 or application of a BRs biosynthesis inhibitor to young panicles markedly decreased OsAPO2 and OsTAW1 expression levels, BRs and AsA contents, activities of enzymes involved AsA synthesis and recycle, NSC amount in rice panicles and spikelet differentiation but increased the $\mathrm{H}_{2} \mathrm{O}_{2}$ content and spikelet degeneration compared to the control (the wide type or application of water). The opposite effects were observed when exogenous BRs were applied.
\end{abstract}

Conclusions: The results suggest that BRs mediate the effect of soil-drying on spikelet differentiation and degeneration, and elevated BRs levels in rice panicles promote spikelet development under MD by enhancing inflorescence meristem activity, AsA recycle and NSC partitioning to the growing panicles.

Keywords: Ascorbic acid (AsA), Assimilate distribution, Brassinosteroids (BRs), Rice (Oryza sativa L.), Soil-drying, Spikelet differentiation and degeneration

\footnotetext{
* Correspondence: jcyang@yzu.edu.cn

${ }^{1}$ Jiangsu Key Laboratory of Crop Genetics and Physiology/Jiangsu Key Laboratory of Crop Cultivation and Physiology, Agricultural College of Yangzhou University, Yangzhou 225009, China

${ }^{2}$ Jiangsu Co-Innovation Center for Modern Production Technology of Grain

Crops, Yangzhou University, Yangzhou 225009, China

Full list of author information is available at the end of the article
}

(c) The Author(s). 2019 Open Access This article is distributed under the terms of the Creative Commons Attribution 4.0 International License (http://creativecommons.org/licenses/by/4.0/), which permits unrestricted use, distribution, and reproduction in any medium, provided you give appropriate credit to the original author(s) and the source, provide a link to the Creative Commons license, and indicate if changes were made. The Creative Commons Public Domain Dedication waiver (http://creativecommons.org/publicdomain/zero/1.0/) applies to the data made available in this article, unless otherwise stated. 


\section{Background}

The panicle size, an important agronomic trait that makes valuable contributions to the grain productivity in rice (Oryza sativa L.), mainly depends on the number of spikelets on a panicle [1-4]. The final panicle size depends on the developmental processes of both spikelet differentiation and spikelet degeneration [3]. The phenomenon of young spikelet degeneration in cereal crops such as rice occurs frequently and is a serious physiological defect that causes grain yield loss $[3,5,6]$. Therefore, reduction or elimination of spikelet degeneration to increase spikelet number is a 'scientific conundrum' and is critical in increasing grain yield of cereals. Great effort has been made to increase spikelets differentiation and reduction or elimination of spikelet degeneration in rice by agronomic, genetic and molecular approaches [3-5, 7-10]. However, the mechanism involved in spikelet differentiation and degeneration remains unclear.

Drought is the most common abiotic stress inhibiting growth and development during the entire rice life cycle. Reproductive development is extremely vulnerable to water stress, leading to spikelet degeneration and yield loss [10-12]. In contrast, Yang et al. observed that moderate soil-drying during grain filling, which allows plants to rehydrate overnight and does not obviously inhibit photosynthesis, increases the grain-filling rate and grain weight of both rice and wheat (Triticum aestivum L) [13-15]. However, little is known whether and how moderate soil-drying during the panicle development could increase differentiation and decrease degeneration of rice spikelet.

Brassinosteroids (BRs) are a relatively recently discovered group of naturally occurring plant steroid hormones that are essential for normal plant growth, development and stress tolerance through producing an array of metabolism changes, and they have wide ranging biological activity and are widely distributed throughout whole plant $[3,16,17]$. However, it is little known whether BRs in young rice panicles respond to soil-drying during panicle development and thereby regulate spikelet differentiation and degeneration.

Usually, drought results in potentially damaging effects through the deleterious production of reactive oxygen species (ROS), such as hydrogen peroxide $\left(\mathrm{H}_{2} \mathrm{O}_{2}\right)$, which is believed to be the main factor in damaging spikelet development of rice [3, 18-20]. However, moderate soil-drying during grain filling has been shown to reduce the $\mathrm{H}_{2} \mathrm{O}_{2}$ content in the grain, leading to increases in the grain-filling rate and grain weight in rice [21]. Our previous work showed that BRs in rice plants can mediate the effects of nitrogen fertilization on spikelet development by decreasing $\mathrm{H}_{2} \mathrm{O}_{2}$ levels during panicle development [3]. To eliminate ROS, plants have developed a complex AOS, including, enzymes and antioxidant molecules, such as ascorbic acid (AsA) [22, 23]. Besides, sugars are not only as a major source of carbon and energy but also have a signaling role in many physiological processes, including the network mechanism related to spikelet development in rice, and some key genetic and molecular switches recently identified from rice, that play critical role in regulating inflorescence development and grain yield [7, 10, 24]. It is interesting to know whether BRs can regulate spikelet development by manipulating AsA and sugars metabolism, and key inflorescence development genes expressions in young rice panicles under soil-drying during panicle development.

The objective of this study was to test the hypothesis that BRs mediate the effect of soil-drying on rice spikelet differentiation and degeneration. Three soildrying treatments, well-watered (WW), moderate soildrying (MD) and severe soil-drying (SD), were conducted during panicle development. The temporal patterns of BRs levels/ or BRs synthesis gene expression, and the expressions of key genes involved in inflorescence development, changes in the levels of the AsA and its synthesis and metabolism related genes expressions/ or enzymes activities, and the $\mathrm{H}_{2} \mathrm{O}_{2}$ content in young panicles were determined. Transgenic plants and chemical regulators were used to verify the role of BRs in rice spikelet differentiation and degeneration.

\section{Results}

Leaf and panicle osmolality, leaf photosynthetic rate and leaf area index (LAI)

Leaf osmolality showed a small change during the day for WW plants and was significantly increased during the day for MD and SD plants, with a larger increase for the SD plants than for the WW plants (Fig. 1a). The predawn $(0600 \mathrm{~h})$ leaf osmolality of MD plants were not significantly different from that of WW plants but was significantly lower than that of SD plants (Fig. 1a). In contrast to the large increase in leaf osmolality, the diurnal changes in panicle osmolality remained constant at midday (Fig. 1b). Panicle osmolality was not significantly different between WW and MD plants, whereas it was significantly higher in SD plants (Fig. 1b), indicating that MD plants were able to rehydrate overnight and well maintain the water status in their young panicles during the day, whereas SD plants were seriously inhibited by soil-drying.

Consistent with plant water status, the photosynthetic rate of leaves and LAI did not differ significantly between WW and MD plants, whereas they were significantly lower in SD plants (Fig. 1c, d). 

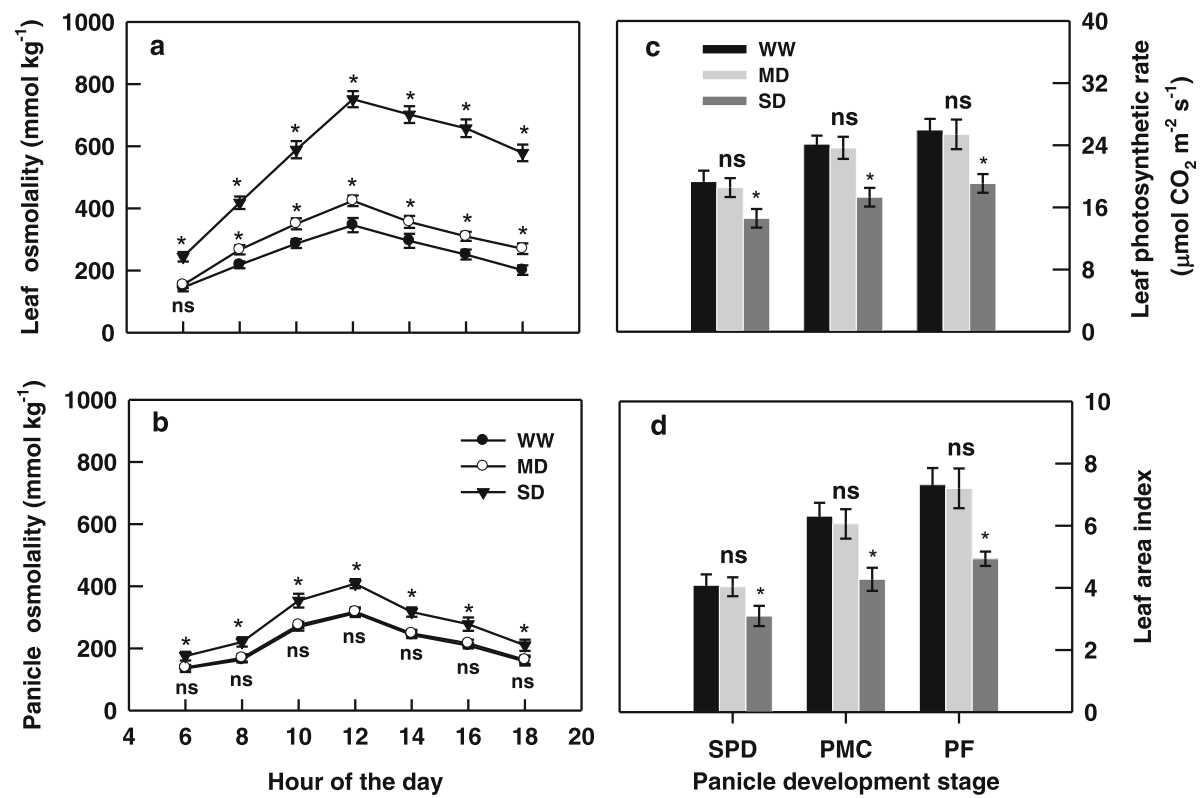

Fig. 1 Changes in osmolality of upmost fully-expanded leaves (a) and panicles (b), photosynthetic rate of the upmost fully-expanded leaves (c) and leaf area index (LAI) (d) of the rice cultivar YD-6 under well-watered (WW), moderate soil-drying (MD) and severe soildrying (SD) treatments. SPD, PMC, and PF represent spikelet primordium differentiation, pollen mother cells meiosis, and pollen filling, respectively. Vertical bars represent standard error of the mean (since the panicle and leaf osmolality at the three stages showed the same tendencies, the data are presented on average of the three stages and $n=18 ; n=6$ for leaf photosynthetic and LAI) where these exceed the size of the symbol. The asterisk $\left(^{*}\right)$ represents significant difference $(P=0.05)$ between the MD regime and the WW regime or between the SD regime and the WW regime within the same measurement date. "ns" represents non-significant at $P=0.05$ between the $M D$ regime and the $W W$ regime

\section{Nonstructural carbohydrates (NSC) accumulation and distribution}

Change in the amount of NSC in the shoot was consistent with leaf photosynthetic rate under various soil moisture treatments. The amount of NSC in the shoot exhibited no significant difference between the WW and MD treatments, whereas was greatly decreased under the SD treatment (Fig. 2a). The MD treatment markedly increased the amount of NSC in young panicles, and the SD treatment significantly decreased it when compared with the WW treatment (Fig. 2b). Opposite to the NSC accumulation in the shoot, the rate of NSC partitioning to the growing young panicle was increased with the increase in soildrying degrees (Fig. 2c). The NSC was most partitioned to the growing young panicle under the SD, intermediate under the $\mathrm{MD}$, and the least in the WW treatment, suggesting that soil-drying during panicle development enhances the partitioning of assimilates from vegetative tissues to growing young panicles of rice.

\section{Changes in genes expressions, enzymes activities and contents of BRs, AsA and $\mathrm{H}_{2} \mathrm{O}_{2}$}

The MD treatment significantly increased, whereas the SD treatment significantly decreased, the expression levels of the key BRs synthesis gene OsD11, key inflorescence development genes OsAPO2 and OsTAW1, AsA synthesis and metabolic related genes OsMPG1, OsDHAR1, OsMDHAR3, OsAPX1, OsAPX2, and key sugar partitioning and metabolism gene OsCSA in rice young panicles (Additional file 1: Fig. S1a-c and Fig. S3a). Changes in the activities of ascorbic acid peroxidase (APX), dehydroascorbate reductase (DHAR) and monodehydroascorbate reductase (MDHAR), contents of 24epiCS, 28-homoBL and AsA in young panicles were very similar to those of OsD11, OsMPG1, OsDHAR1, OsMDHAR3, OsAPX1, OsAPX2, OsAPO2, OsTAW1, and OsCSA expression levels. They were significantly higher in the MD treatment and significantly lower in the SD treatment than in the WW treatment (Fig. 3a-c, e-g; Additional file 1: Fig. S1a-c and Fig. S3a). In contrast to the AsA content, the $\mathrm{H}_{2} \mathrm{O}_{2}$ content was significantly decreased under the $\mathrm{MD}$, and significantly increased under the SD treatment (Fig. 3d).

\section{Spikelet development and grain yield}

Compared with the WW treatment, the MD treatment significantly increased differentiated spikelet number and panicle size, and significantly decreased spikelet degeneration rate. The SD treatment showed 


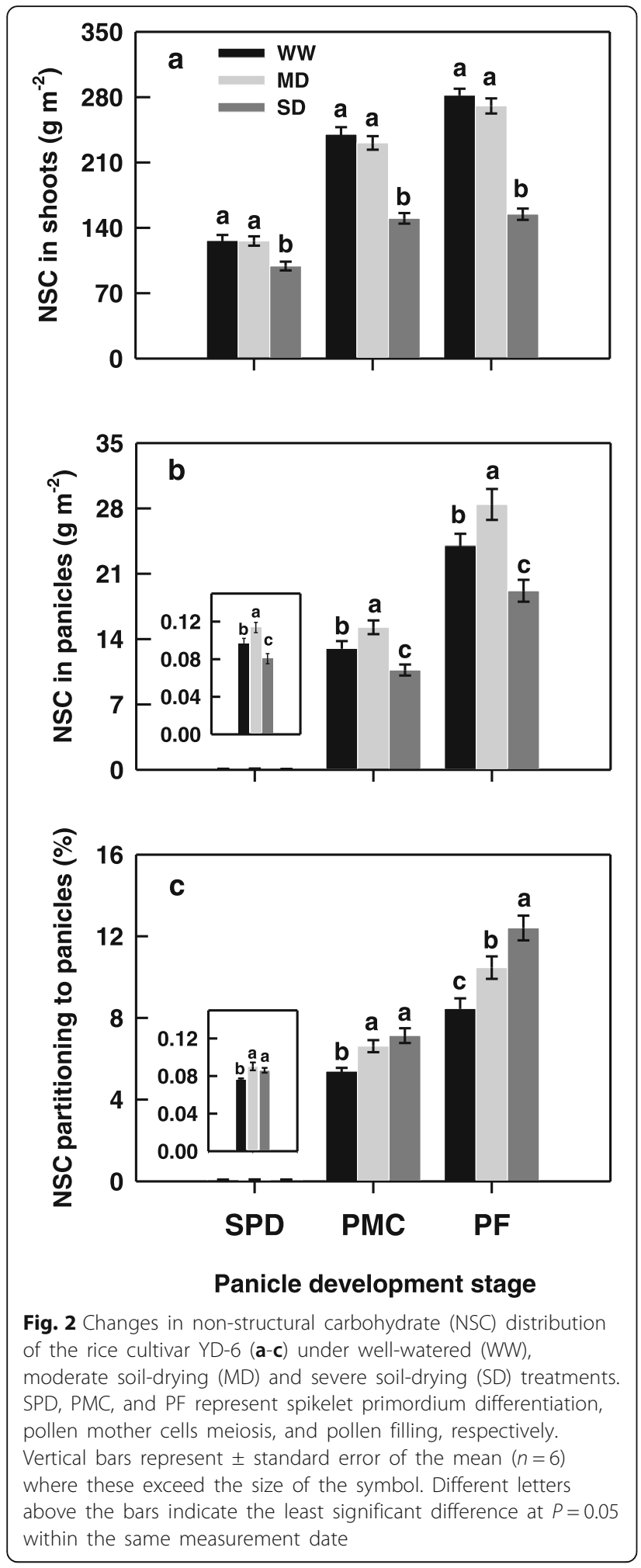

the opposite effects (Fig. 4a-c). As a result, the MD treatment significantly increased total number of spikelets and grain yield, whereas the SD markedly decreased those relative to the WW treatment (Table 1).
Effects of MD on RNA interference (RNAi) line

To understand the molecular mechanism through which BRs regulate spikelet development in rice, we used an RNAi line of transgenic rice in which the OsD11 gene encoding a cytochrome P450 enzyme (CYP724B1) involved in BRs biosynthesis had reduced expression (D11-RNAi 1, called DR-1), and its wild type (WT) was the inbred japonica rice cultivar Zhonghua 10 (ZH10). The $D R-1$ plants exhibited a typical phenotype of rice plants with reduced BRs levels, that is, the plant size and degree of lamina joint bending were both lower than those in the wide type (WT) plants (Fig. 5a). The DR-1 plants displayed a significant reduction in the differentiated spikelet number and significant increases in spikelet degeneration rate compared to the WT plants (Fig. 5bh). Consistent with the phenotype of the $D R-1$ plants, the OsD11, OsAPO2, OsTAW1, OsCSA, OsMPG1, OsDHAR1, OsMDHAR3, OsAPX1 and OsAPX2 expression levels, BRs (24-epiCS and 28-homoBL) and AsA contents, and NSC amount, and APX, DHAR and MDHAR activities were significantly lower, whereas the $\mathrm{H}_{2} \mathrm{O}_{2}$ content was significantly higher, in $D R-1$ panicles than in WT panicles in the WW and MD treatments (Fig. 6aj; Additional file 1: Fig. S2a-f and Fig. S3b).

The MD treatment significantly increased expression levels of OsD11, OsAPO2, OsTAW1, OsCSA, OsMPG1, OsDHAR1, OsMDHAR3, OsAPX1 and OsAPX2, contents of BRs (24-epiCS and 28-homoBL), AsA and NSC, activities of APX, DHAR and MDHAR, and differentiated spikelet number, whereas significantly decreased $\mathrm{H}_{2} \mathrm{O}_{2}$ content in young panicles and spikelet degeneration rate of WT plants. However, the MD treatment had no significant effects on these characteristics in the DR-1 plants (Fig. 5a-h and Fig. 6a-j; Additional file 1: Fig. S2a$\mathrm{f}$ and Fig. S3b).

\section{Effect of chemical application}

Compared with no chemical application (CK), the application of brassinazole (BRZ) (an inhibitor of BRs biosynthesis) to WT or YD-6 panicles in the WW treatment significantly decreased the expression levels of OsAPO2, OsTAW1, OsCSA, OsMPG1, OsDHAR1, OsMDHAR3, OsAPX1 and OsAPX2, contents of BRs (24-epiCS + 28homoBL), AsA and NSC, and activities of APX, DHAR and MDHAR, significantly increased $\mathrm{H}_{2} \mathrm{O}_{2}$ content in young panicles, and significantly decreased the differentiated spikelet number and increased spikelet degeneration rate. The opposite effects were observed when BRs (24-epiCS +28-homoBL) were applied to the panicles of $D R-1$ or SD treated-YD-6 (Fig. 7a-i; Additional file 1: Fig. S4a, b; Fig. S5a-d and Fig. S6ai). In addition, applied $\mathrm{H}_{2} \mathrm{O}_{2}$ to WT or YD-6 panicles in the WW treatment could significantly increase endogenous $\mathrm{H}_{2} \mathrm{O}_{2}$ content in the panicles, and decrease 



Fig. 3 Changes in contents of brassinosteroids (BRs) $(\mathbf{a}, \mathbf{b})$, ascorbic acid (AsA) (c) and hydrogen peroxide $\left(\mathrm{H}_{2} \mathrm{O}_{2}\right)(\mathbf{d})$, and activities of ascorbic acid peroxidase (APX) (e), dehydroascorbate reductase (DHAR) (f) and monodehydroascorbate reductase (MDHAR) ( $\mathbf{g}$ ) in young panicle of the rice cultivar YD-6 under well-watered (WW), moderate soil-drying (MD) and severe soil-drying (SD) treatments. SPD, PMC, and PF represent spikelet primordium differentiation, pollen mother cells meiosis, and pollen filling, respectively. Vertical bars represent \pm standard error of the mean $(n=$ 6) where these exceed the size of the symbol. Different letters above the bars indicate the least significant difference at $P=0.05$ within the same measurement date

the differentiated spikelet number and increase spikelet degeneration rate, whereas application of AsA or AsA combined with sucrose to $D R-1$ or SD treatedYD-6 panicles could significantly decrease endogenous $\mathrm{H}_{2} \mathrm{O}_{2}$ content in the panicles, and consequently, increase the differentiated spikelet number and decrease spikelet degeneration rate (Additional file 1: Fig. S7a-f).

\section{Discussion}

Effect of soil-drying during panicle development on rice spikelet differentiation and degeneration

The growth period from meiosis to flowering in cereal crops is generally thought to be very sensitive to environmental changes, and spikelet degeneration is increasingly subjected to drought during this period [10-12]. In our study, a SD treatment imposed during panicle development significantly decreased spikelet differentiation and increased spikelet degeneration (Fig. 4a-c). However, the MD treatment not only promoted spikelet differentiation, but also effectively suppressed spikelet degeneration, leading to more spikelets per rice panicle, a higher grain yield than the WW treatment (Table 1; Fig. 4a-c). We argue that the susceptibility of rice to soil-drying during panicle development varies with the degree of soil drying, and that moderate soil-drying, that is, soil water potential is not lower than $-15 \mathrm{kPa}$ or the osmolality of a young panicle is no more than $300 \mathrm{mmol} \mathrm{kg}^{-1}$, benefits spikelet growth and development. This finding would have great significance to improve spikelet development of rice, especially for the newly bred 'super' rice which exhibits more numerous spikelets potential and higher frequency of degenerated spikelets $[3,5,10]$. 



Fig. 4 Spikelet development of the rice cultivar YD-6 under well-watered (WW), moderate soil-drying (MD) and severe soil-drying (SD) treatments. (a) Panicle morphology of YD-6 under various soil-drying treatments at maturity. Bar $=5 \mathrm{~cm}$; $\mathbf{b}, \mathbf{c})$ Comparisons of differentiated spikelets per panicle and spikelet degeneration rate under various soil-drying treatments. The arrow indicates the obvious degenerated spikelets in a. Vertical bars represent \pm standard error of the mean $(n=6)$ where these exceed the size of the symbol. Different letters above the bars indicate the least significant difference at $P=0.05$

\section{BRs mediate the effect of soil-drying on rice spikelet differentiation and degeneration}

The mechanism by which soil-drying, especially MD improves panicle development in rice remains unclear. It is proposed that the increase in BRs biosynthesis would enhance the role of BRs in regulating plant growth and development and responsing to environmental stresses $[3,16,17,25-28]$. The gene OsD11 is believed to belong to the cytochrome P450 superfamily and function in the BRs biosynthesis pathway in rice, and over expression of OsD11 at a suitable level could increase grain size, grain number and grain yield in rice [29, 30]. The MD significantly increased, whereas the SD markedly decreased, the
OsD11 expression level and contents of 24-epiCS and 28homoBL in young rice panicles (Fig. 3a, b; Additional file 1: Fig. S1a-c). The OsD11 expression level, 24-epiCS and 28homoBL contents of young panicles were highly consistent with differentiated spikelet number and showed a trend opposite to that of the spikelet degeneration rate (Fig. 3a, b and Fig. 4a-c; Additional file 1: Fig. S1a-c). The DR-1 plants showed significant reduction in OsD11 expression level, 24epiCS and 28-homoBL contents and differentiated spikelet number, and significant increases in spikelet degeneration rate compared with the WT plants in both the WW and MD treatments. The results herein also showed that the MD treatment significantly increased the OsD11 expression

Table 1 Grain yield and yield components of the rice cultivar YD-6 subjected to various soil moisture treatments ${ }^{1)}$

\begin{tabular}{|c|c|c|c|}
\hline \multirow[t]{2}{*}{ Items } & \multicolumn{3}{|c|}{ Soil moisture treatment } \\
\hline & $\overline{W W}$ & $\mathrm{MD}$ & SD \\
\hline Total number of spikelets $\left(\times 10^{3} \mathrm{~m}^{-2}\right)$ & $29.5 \pm 0.69 b^{2)}$ & $33.6 \pm 0.93 a$ & $18.9 \pm 0.38 c$ \\
\hline Fully filled grains (\%) & $88.8 \pm 2.15 \mathrm{a}$ & $89.9 \pm 1.12 \mathrm{a}$ & $72.7 \pm 3.04 b$ \\
\hline 1000-grain weight (g) & $27.8 \pm 0.53 a$ & $27.5 \pm 0.54 a$ & $28.0 \pm 0.68 \mathrm{a}$ \\
\hline Grain yield $\left(\mathrm{g} \mathrm{m}^{-2}\right)$ & $730 \pm 32.3 b$ & $828 \pm 22.3 \mathrm{a}$ & $385 \pm 25.6 c$ \\
\hline
\end{tabular}

${ }^{1)}$ The treatments were well-watered (WW), moderate soil-drying (MD) and severe soil-drying (SD) during young panicle development

${ }^{2)}$ Data are means \pm standard error of six independent measurements and values with different letters indicate statistical difference at $P=0.05$ within the same row 

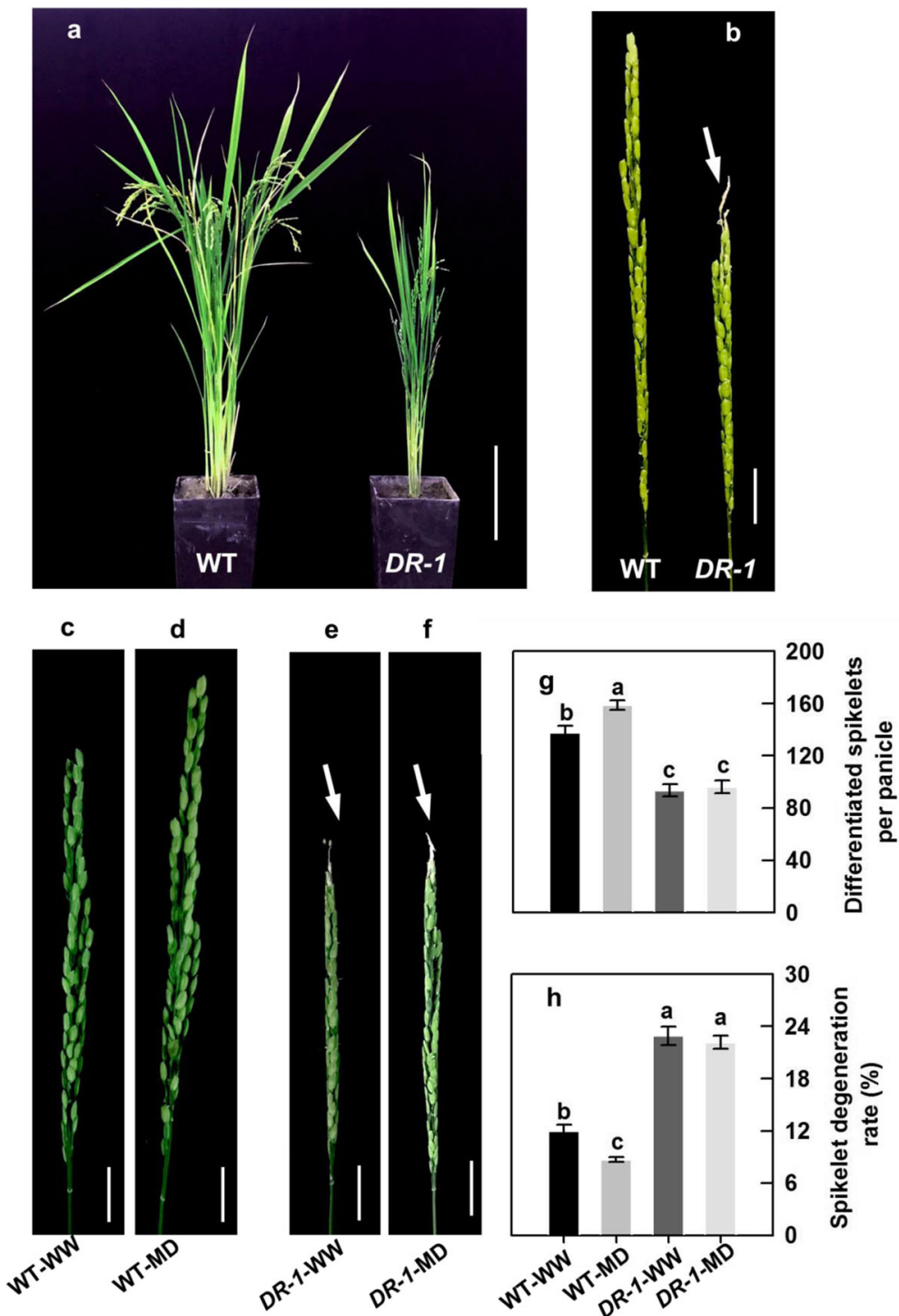

Fig. 5 Phenotypes of wild-type (WT) and D11-RNAi (DR-1) plants under well-watered (WW) and moderate soil-drying (MD) treatments. (a) Gross morphology of an adult WT (Zhonghua 10, ZH10) and DR-1 plants. Bar $=30 \mathrm{~cm}$; (b) Comparison of representative panicle of $D R-1$ with the WT at pollen filling stage. (c-f) Panicle morphology of WT and DR-1 under various soil-drying treatments during panicle development. Bars $=2 \mathrm{~cm} ;(\mathbf{g}, \mathbf{h})$ Comparisons of differentiated spikelets number and spikelet degeneration rate of DR-1 with the WT under various soil soil-drying treatments. The arrow indicates the obvious degenerated spikelets in $b$, e and f. Vertical bars represent \pm standard error of the mean $(n=6)$ where these exceed the size of the symbol. Different letters above the bars indicate the least significant difference at $P=0.05$

level, BRs (24-epiCS and 28-homoBL) contents and differentiated spikelet number, and decreased the spikelet degeneration rate of the WT plants, whereas exhibited no distinct effect on the OsD11 expression level, BRs content, spikelet differentiation and degeneration of $D R-1$ plants (Fig. 5a-h and Fig. 6a, b; Additional file 1: Fig. S2a). When BRs (24-epiCS + 28-homoBL) were applied to young panicles of DR-1 or SD treated-YD-6, the BRs levels and differentiated spikelet number were significantly increased, whereas the spikelet degeneration rate was significantly decreased when compared to the control. The opposite effects were observed when BRZ, an inhibitor of BRs biosynthesis, was applied to young panicles of WT or WW treated-YD-6 (Fig. 7a-d, k, 1; Additional file 1: Fig. S6a, h, i). The results imply that the more enhanced BRs biosynthetic activity (the OsD11 expression level) in rice panicles under MD contributes to higher levels of 24-epiCS and 28-homoBL, leading to more differentiated spikelet number, and decreases in spikelet degeneration rate, and consequently, to a significant increase in grain yield. In contrast, the decreases in BRs synthesis in the SD treatment inhibited spikelet development and, as a result, led to a low grain yield. 


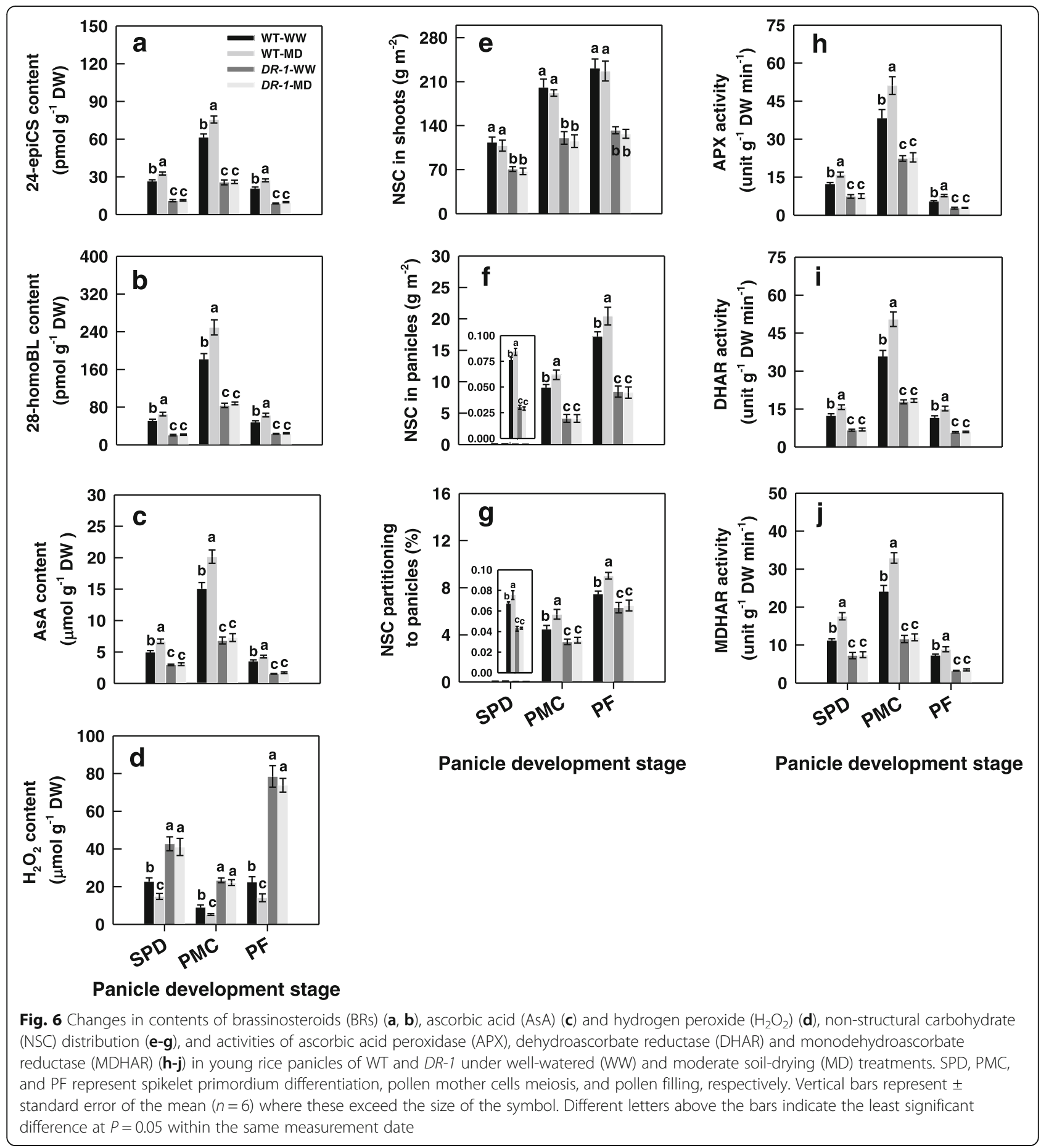

Mechanism underlying BRs regulate rice differentiation and degeneration

Little is known about how BRs regulate spikelet development in rice. Previous studies have shown that the spikelet number per panicle is closely correlated with amount of the available NSC in rice [24,31]. The results herein showed that soil-drying promoted the re-allocation of NSC from the vegetative tissues to growing panicles
(Fig. 2a-c and Fig. 6e-g). The SD markedly increased spikelet degeneration rate, decreased the amount of NSC in young panicles, differentiated spikelets and grain yield although the rate of NSC partitioning to the growing young panicle was increased, implying that the growing panicle from an enhanced NSC remobilization could not compensate for the photosynthesis loss during the panicle development under such a treatment (Fig. 1c, d; Fig. 

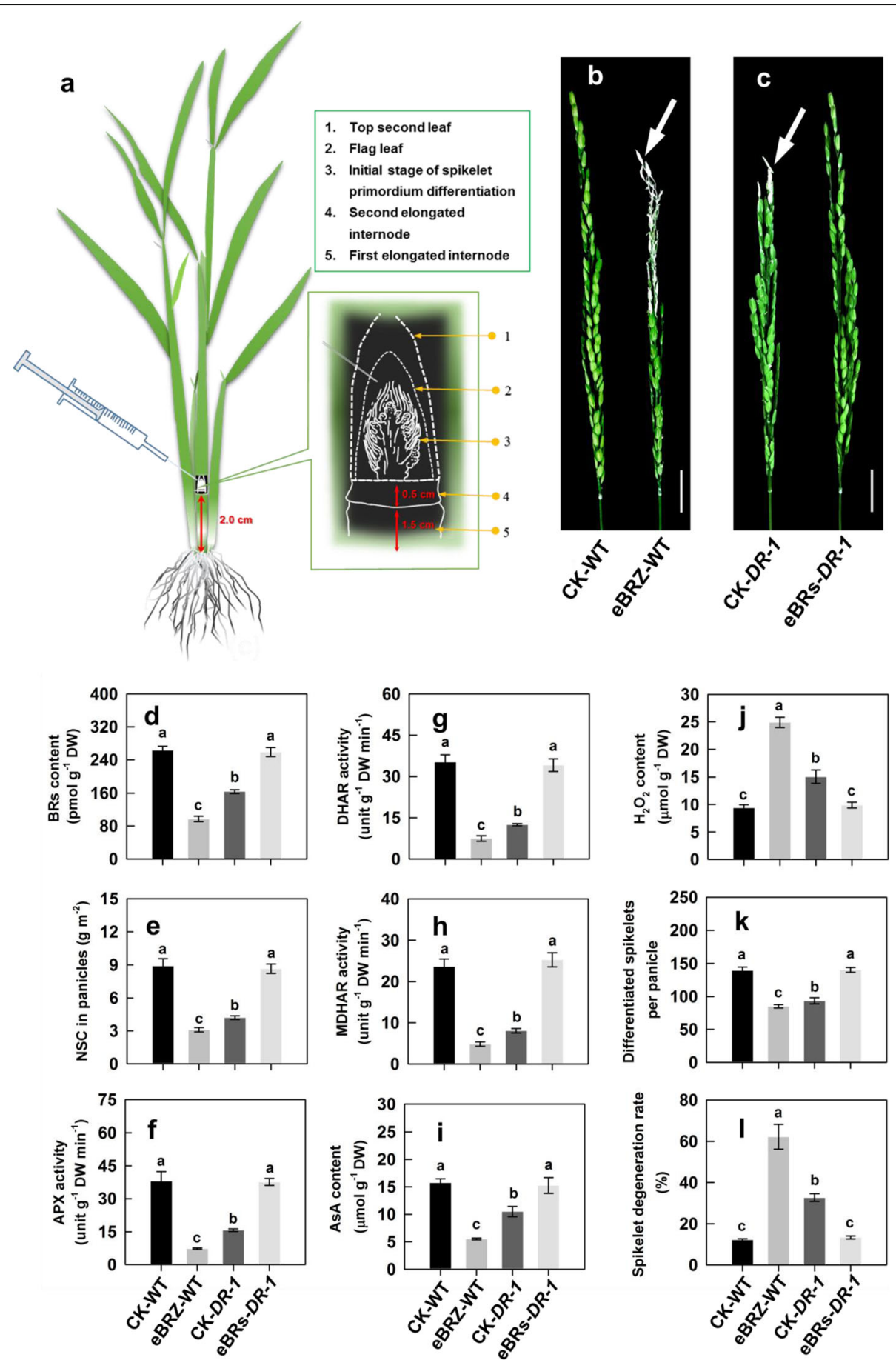

Fig. 7 Effect of exogenous brassinosteroids (BRs) and brassinazole (BRZ) on physiological traits and spikelet development of WT and DR-1 plants. (a) Schematic diagram of the initial stage of spikelet primordium differentiation and the injection site in the chemical treatment experiment; (b, c) Panicle phenotypes of WT and DR-1 under various chemical regulators treatments. Bars $=2 \mathrm{~cm}$. The arrow indicates the obvious degenerated spikelets; (d-j) Changes in contents of BRs (24-epiCS + 28-homoBL), NSC, AsA and $\mathrm{H}_{2} \mathrm{O}_{2}$, activities of APX, DHAR, and MDHAR in young rice panicles; (k, I) Spikelet development under various chemical regulators treatments. CK: Panicles received deionized water; eBRZ: Panicles received $10 \mathrm{nmol} \mathrm{L}{ }^{-1}$ brassinazole (BRZ, an inhibitor of BRs biosynthesis); eBRs: Panicles received $10 \mathrm{nmol} \mathrm{L}{ }^{-1}$ BRs (24-epiCS +28 -homoBL). Vertical bars represent \pm standard error of the mean $(n=6)$ where these exceed the size of the symbol. Different letters above the bars indicate the least significant difference at $P=0.05$ 
2a-c and Fig. 4a-c). Over-expression of BRs biosynthetic or BRs-signaling genes can increase expression of OsCSA which encodes a MYB domain protein and directly triggers expression of genes relating to sugar partitioning, cleavage and uptake and starch synthesis in reproductive organs, and increased seed size and weight in rice [32, 33]. Moreover, some genes such as OsAPO2 and OsTAW1 are known to be critical for controlling rice spikelet numbers by inhibiting the precocious transition from inflorescence meristem to spikelet meristem, and their overexpression displayed a prolonged inflorescence meristem activity and delayed spikelet specification, causing prolonged branch development and increased spikelet numbers [7]. We found, however, the MD not only substantially enhanced the rate of NSC partitioning to the growing panicles, but also improved the BRs (24epiCS and 28-homoBL) contents, expression levels of OsAPO2 and OsTAW1 and differentiated spikelet number, and decreased spikelet degeneration rate of both YD-6 and WT, whereas the panicles of $D R-1$ or SD treated-YD-6, which showed reduction in OsD11 expression, BRs contents, expression levels of OsAPO2, OsTAW1 and OsCSA, and NSC amount, resulted in less differentiated spikelet number and more spikelet degeneration rate compared with those in control conditions, however, the MD had no distinct effect on those of DR-1 plants (Fig. 2a-c; Fig. 3a, b; Fig. 4a-c; Fig. 5a-h and Fig. 6a, b, e-g; Additional file 1: Fig. S1a-c; Fig. S2a, b and Fig. S3a, b). When BRs (24-epiCS +28-homoBL) were applied to the young panicles of $D R-1$ or SD treated-YD-6, the expression levels of OsAPO2, OsTAW1 and OsCSA, and NSC amount in young panicles were significantly increased, the spikelet degeneration rate was decreased and differentiated spikelet number was increased, whereas application of an inhibitor of BRs biosynthesis to the young panicles of WT or WW treated-YD-6 showed the opposite effects (Fig. 7a-e, k, l; Additional file 1: Fig. S4a, b; Fig. S5a-d and Fig. S6a, b, h, i). Therefore, we conclude that if a soil-drying is applied during panicle development to a degree that overnight rehydration can be completed, water retention in growing panicle and photosynthesis is not too severely inhibited, then the growing panicle can get more NSC from vegetative tissues and can outweigh the small loss of photosynthesis, and also get prolonged inflorescence meristem activity by increasing BRs levels in growing rice panicles.

AOS include antioxidant enzymes and antioxidant molecules such as AsA play a fundamental role in scavenging ROS due to its powerful antioxidant properties, and AsA can be modified by exogenous BRs treatment [3, 22, 28, 34]. Moreover, the metabolic responses to drought stress are an indirect response to oxidative stress, rather than direct responses to drought stress, and excessive production and accumulation of ROS such as $\mathrm{H}_{2} \mathrm{O}_{2}$ can damage the cellular membrane and cause rice spikelet damage
[35]. In plants, GDP-D-mannose as a precursor of AsA, can be synthesized by GDP-D-mannose pyrophosphorylase (GMPase) [36]. It is proposed that AsA as a major antioxidant, is firstly oxidized into an unstable short-lived monodehydroascorbate (MDHA) by ascorbic acid oxidase (AO) and APX [37], and then some MDHAs are reduced to AsA by MDHAR, and other MDHAs are converted into AsA and dehydroascorbate (DHA) through spontaneous disproportionation, and DHA must be converted to AsA by DHAR in a reaction requiring reduced glutathione (GSH) [38]. In this process, DHAR is a key factor in maintaining a reduced pool of AsA [18]. We observed that the panicles of $D R-1$ or SD treated-YD-6, which showed a significantly less differentiated spikelet number and higher spikelet degeneration rate, were accompanied by decreased BRs contents, expression levels of OsMPG1, OsDHAR1, OsMDHAR3, OsAPX1 and OsAPX2, lower activities of APX, DHAR and MDHAR, and higher content of $\mathrm{H}_{2} \mathrm{O}_{2}$ than the panicles of WT or WW treated-YD-6, whereas those in the DR-1 panicles were not significantly affected by the MD treatment (Fig. 3a-g; Fig. 4a-c; Fig. 5a-h and Fig. 6a-d, h-j; Additional file 1: Fig. S1a-c; Fig. S2c-f; Fig. S4a, b and Fig. S6c-i). Application of BRs (24-epiCS + 28-homoBL) to young panicles of DR-1 or SD treated-YD-6 elevated the BRs content there. Simultaneously, the expression levels of OsMPG1, OsDHAR1, OsMDHAR3, OsAPX1 and OsAPX2, the activities of APX, DHAR and MDHAR and AsA content in rice panicles were markedly increased, whereas the $\mathrm{H}_{2} \mathrm{O}_{2}$ content was considerably decreased, and as a result, the differentiated spikelet number was increased, and the spikelet degeneration rate was significantly decreased. The opposite effects were observed when BRZ was applied to the young panicles of WT or WW treatedYD-6 (Fig. 7a-d, f-l; Additional file 1: Fig. S4a, b and Fig. S6a, c-i). Furthermore, soluble sugars can also scavenge the deleterious effect induced by $\mathrm{H}_{2} \mathrm{O}_{2}$ [31]. We also observed that the effect of applying $\mathrm{H}_{2} \mathrm{O}_{2}$ on spikelet development was very similar with that of applying BRZ, and the effects of applying AsA or AsA combined with sucrose on $\mathrm{H}_{2} \mathrm{O}_{2}$ level and spikelet development were very similar with that of applying BRs, and applying AsA combined with sucrose showed the better effects to decrease $\mathrm{H}_{2} \mathrm{O}_{2}$ accumulation in young panicle and enhance spikelet development than only AsA was applied (Additional file 1: Fig. S7a-e). These results indicate that the elevated BRs levels under the MD treatment could enhance AsA synthesis and recycle, and NSC remobilization to protect spikelet growth and development from the deleterious effect of $\mathrm{H}_{2} \mathrm{O}_{2}$ (Fig. 8).

It is noteworthy that the responses of indica cultivar (YD-6) and japonica cultivar (ZH10) to the MD and BRs application were very similar. Furthermore, treatment with exogenous BRs, the injury of $\mathrm{SD}$ on rice spikelet 


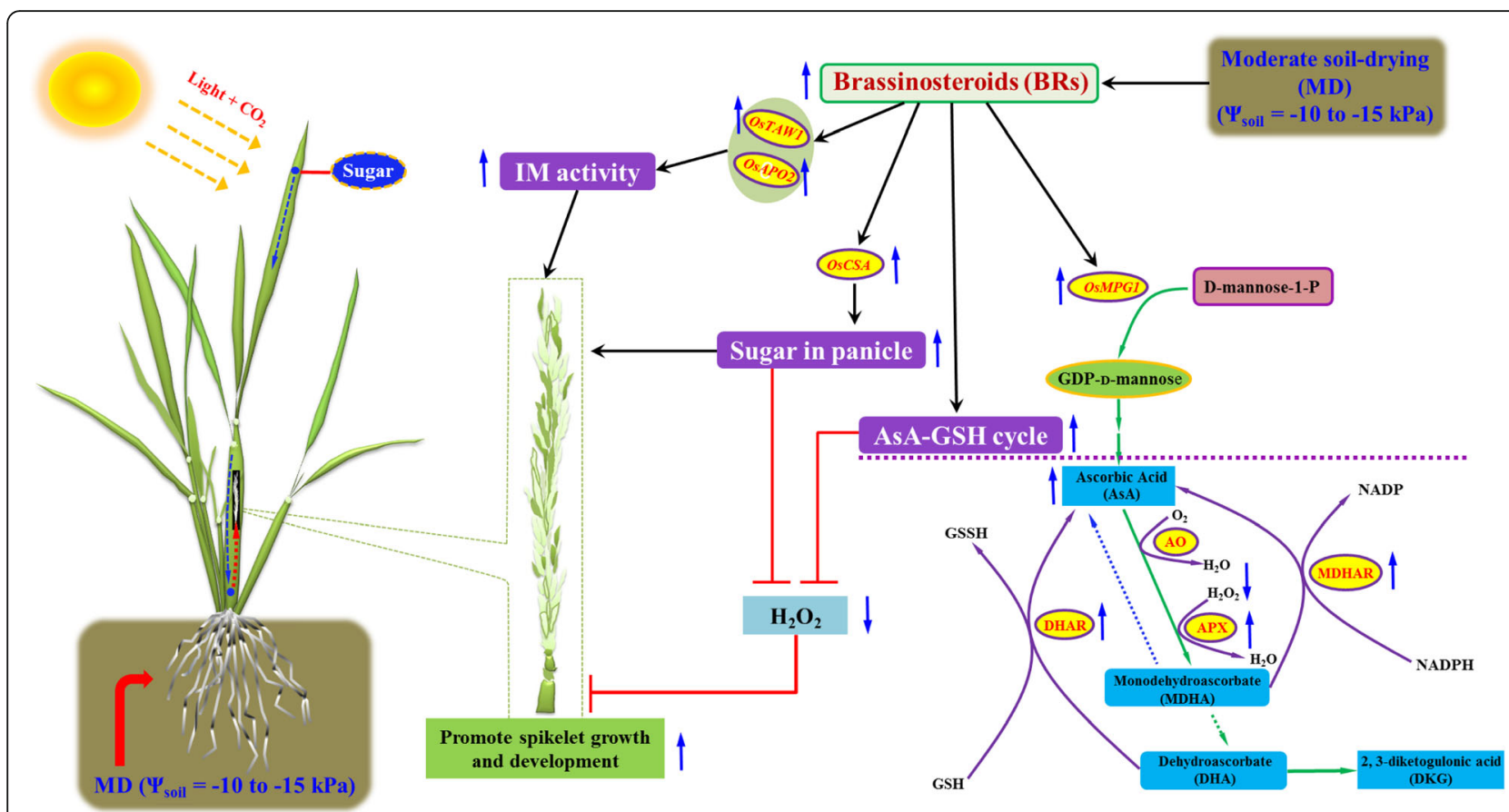

Fig. 8 The descriptive model of brassinosteroids (BRs) function in spikelet development under moderate soil-drying (MD) treatment during rice panicle development. Under MD treatment, photosynthesis is not severely inhibited, and the growing panicle can get more NSC from vegetative tissues, and also get prolonged inflorescence meristem (IM) activity, and the AsA synthesis and recycle (AsA-GSH cycle) were enhanced to protect spikelet growth and development from the deleterious effect of $\mathrm{H}_{2} \mathrm{O}_{2}$ in panicles by increasing BRs level in growing panicles. The black arrow " $\rightarrow$ " indicates enhancement, while red " $\dashv "$ indicates inhibition. Up-regulated items under the MD treatment are marked with upward blue arrows, and down-regulated items under the MD treatment are marked with downward blue arrows

development could be relieved effectively. These results demonstrate that an increase in BRs biosynthesis is an important approach to enhance spikelet development and grain yield, and MD imposed during the young panicle development period is an effective technology to increase spikelet differentiation and decrease spikelet degeneration in rice.

\section{Conclusion}

Moderate soil-drying imposed during the young panicle development period can increase spikelet differentiation and decrease spikelet degeneration of rice. The enhanced spikelet development under MD is closely associated with an increase in BRs biosynthesis in young rice panicles. In contrast, the severe soil-drying decreases BRs synthesis, and consequently, results in the decrease in spikelet differentiation and increase in spikelet degeneration. BRs mediate the effect of soil-drying on spikelet differentiation and degeneration by regulating inflorescence meristem activity, AsA recycle and NSC partitioning to the growing panicles.

\section{Methods}

\section{Materials and culture conditions}

The experiment was conducted at a research farm of Yangzhou University, Jiangsu Province, China $\left(32^{\circ} 30^{\prime} \mathrm{N}\right.$, $119^{\circ} 25^{\prime} \mathrm{E}$ ), during the rice-growing season (May-October). The soil was a sandy loam (Typic Fluvaquent, Entisol, US classification) that contained $24.2 \mathrm{~g} \mathrm{~kg}^{-1}$ organic matter, $101.5 \mathrm{mg} \mathrm{kg}^{-1}$ alkali-hydrolysable nitrogen $(\mathrm{N})$, $34.2 \mathrm{mg} \mathrm{kg}^{-1}$ Olsen phosphorus and $68.1 \mathrm{mg} \mathrm{kg}^{-1}$ exchangeable potassium. The field-capacity soil moisture content measured gravimetrically at a constant drainage rate was $0.187 \mathrm{~g} \mathrm{~g}^{-1}$, and the bulk density of the soil was $1.34 \mathrm{~g} \mathrm{~cm}^{-3}$. A rice (Oryza sativa L.) cultivar currently used in local production, namely, Yangdao-6 (YD-6, an inbred indica cultivar), was grown in the field. Seeds were sown in the paddy field on 11 May. Thirty-day-old seedlings were then transplanted into the field with a hill spacing of $0.25 \mathrm{~m} \times 0.16 \mathrm{~m}$ and two seedlings per hill. Nitrogen $\left(\mathrm{N}, 80 \mathrm{~kg} \mathrm{ha}^{-1}\right.$ as urea), phosphorus $\left(30 \mathrm{~kg} \mathrm{ha}^{-1}\right.$ as single superphosphate) and potassium $\left(40 \mathrm{~kg} \mathrm{ha}^{-1}\right.$ as $\mathrm{KCl})$ were applied and incorporated before transplanting. $\mathrm{N}$ as urea was also applied at mid-tillering $\left(40 \mathrm{~kg} \mathrm{ha}^{-1}\right)$, panicle initiation $\left(40 \mathrm{~kg} \mathrm{ha}^{-1}\right)$, and at spikelet primordium differentiation (SPD) $\left(40 \mathrm{~kg} \mathrm{ha}^{-1}\right)$. The developmental stages were observed by frequent inspections of meristems and leaf remainder (LR) as described by Ling et al. (1983) [39]. Panicle initiation was defined as the first appearance of a differentiated apex (LR: 4.0-3.5) and SPD as the appearance of glumous flower primordia at the tips of elongating primary rachis branches (the length of young 
panicles was approximately $1.0-1.5 \mathrm{~mm}$; LR: $2.0-1.6)$. Except for drainage at the end tillering (12-15 July), the water level in the field was keep at the $1-2 \mathrm{~cm}$ until the onset of panicle initiation (21-25 July) when soil-drying treatments were initiated. The cultivar headed on 24-26 August (50\% of plants) and was harvested on 15-16 October.

\section{Treatments}

The experiment followed a one by three ( 1 cultivar and 3 levels of soil moisture) factorial design with three treatments. Each of the treatments included three replicate plots in a complete randomized block design. The plot size was $5 \mathrm{~m} \times 6 \mathrm{~m}$, and the plots were separated by an alley $1-\mathrm{m}$ wide with plastic film inserted into the soil to a depth of $50 \mathrm{~cm}$ to form a barrier. From the onset of panicle initiation to the heading time, three soil moisture treatments, WW, MD, and SD, were imposed on the plants. Plots with the WW treatment were flooded with water to a 1 to $2-\mathrm{cm}$ depth by manually supplying tap water [soil water potential $\left(\Psi_{\text {soil }}\right)$ at 0 kilopascals $(\mathrm{kPa})$ ]. In the MD treatment, $\Psi_{\text {soil }}$ at a 15 to 20 -cm depth was maintained at -10 to $-15 \mathrm{kPa}$ (soil moisture content: $\left.0.170-0.175 \mathrm{~g} \mathrm{~g}^{-1}\right)$, and in the SD treatment, $\Psi_{\text {soil }}$ at a 15 to $20-\mathrm{cm}$ depth was maintained at -30 to $-35 \mathrm{kPa}$ (soil moisture content: $0.145-0.150 \mathrm{~g} \mathrm{~g}^{-1}$ ). Soil water potentials of -10 to $-15 \mathrm{kPa}$ in the $\mathrm{MD}$ regime and -30 to $-35 \mathrm{kPa}$ in the SD regime were chosen based on our earlier work $[10,40]$, which showed that a mild soildrying regime $\left(\Psi_{\text {soil }}=-10\right.$ to $-15 \mathrm{kPa}$ at a 15 to $20-\mathrm{cm}$ depth) during the growing season did not reduce grain yield but a severe soil-drying regime $\left(\Psi_{\text {soil }}=-30 \mathrm{kPa}\right)$ reduced yield by as much as $40 \%$ compared to the WW regime. Soil water potential was monitored at a 15-20$\mathrm{cm}$ soil depth by five tensiometers (Institute of Soil Science, Chinese Academy of Sciences, Nanjing, China) in each plot. Tensiometer readings were recorded every $3 \mathrm{~h}$ from $0600 \mathrm{~h}$ to $1800 \mathrm{~h}$. When the reading dropped to the designated value, $100 \mathrm{~L}$ and $60 \mathrm{~L}$ of tap water per plot was added manually to plots with the MD and SD treatments, respectively. Each block was protected from rain by a rain shelter consisting of a steel frame covered with a plastic sheet during rainfall events to minimize the effect of rainfall on the treatments; the shelters were removed after each rainfall event.

\section{Sampling}

Six hundred main stems were tagged in each plot during the tillering period. One hundred young panicles were sampled from the tagged stems in each plot at the stages of SPD, PMC (the spikelet length was about $50 \%$ of the final length of a spikelet; LR: 0.4-0.3), and pollen filling (PF, the spikelet length was about $85 \%$ of the final length of a spikelet; LR: 0.2-0), respectively. In this study, the SPD, PMC and PF were chosen because the rice spikelets are differentiated at SPD, and spikelet degeneration mainly occurs at PMC or PF [5]. Young panicles were collected at each sampling time and used to measure the BRs contents, genes expression levels, and other physiological traits in young panicles.

At the heading stage, 200 young panicles that had emerged from the flag leaf sheath by two-thirds were tagged in each plot to determine the number of differentiated and degenerated spikelets per panicle. The number of differentiated spikelets was defined as the sum of the numbers of developed spikelets and degenerated spikelets. The spikelet degeneration rate was defined as the ratio of degenerated spikelets to differentiated spikelets. Fully filled grains were investigated from plants of a $1 \mathrm{~m}^{2}$ site (excluding the border ones) in each plot at maturity and expressed as the percentage of fully filled spikelets relative to the total number of developed spikelets (sterile spikelets, partially filled spikelets, and fully filled spikelets) in a panicle. Grain weight and grain yield were determined from plants of a $2 \mathrm{~m}^{2}$ site (except border ones) in each plot at maturity. The method used for these observations was described previously [10].

\section{Determination of leaf and panicle osmolality, photosynthetic rate, LAl, and NSC}

At the onset of SPD, PMC and PF stages and when sky was clear, the osmolality of the upmost fully expanded leaves and young panicles was measured at 2-h intervals from predawn $(0600 \mathrm{~h})$ to evening $(1800 \mathrm{~h})$ in one day. The measurements were made by using a pressure osmometer (Vapro 5520, Instrumentation Consultancy Technologies, Wescor, USA), with 6 replications for each plot.

Photosynthetic rate of the upmost fully-expanded leaves was determined at PI, PMC and SPD stages using a gas exchange analyzer (Li-Cor 6400 portable photosynthesis measurement system, Li-Cor, Lincoln, NE, USA) from $0900 \mathrm{~h}$ to $1100 \mathrm{~h}$, when the photosynthetically active radiation above the canopy was $1300-1500 \mu \mathrm{mol} \mathrm{m}^{-}$ ${ }^{2} \mathrm{~s}^{-1}$. The measurements were made on the upper surface of the leaves, with six leaves in each plot. The LAI was measured at the SPD, PMC and PF stages and plants from six hills from each plot were sampled from the third row in order to minimize the border effect. At those stages, the amount of NSC in the shoots (culm + sheath + leaf blade + panicle) was determined according to the method of Yoshida et al. (1976) [41]. The rate of NSC partitioning to young panicles was calculated using the following formula:

NSC partitioning to young panicles $(\%)=$ NSC in young panicles/NSC in the shoots $\times 100(1)$.

\section{Extraction and quantification of BRs}

Endogenous BRs were extracted and purified using the methods of Ding et al. (2013) [42], with modifications. 
Briefly, each sample containing 4-6g of fresh young panicles was ground by a tissue crusher (MM400, Retsch Corp, Haan, Germany), and $0.8 \mathrm{~g}$ of power was transferred into a $10-\mathrm{mL}$ centrifuge tube, followed by extraction with $4 \mathrm{~mL}$ of acetonitrile overnight at $20^{\circ} \mathrm{C}$. Extraction, dehydration and double-layered solid phase extraction (DL/SPE) were performed according to the method of Chen et al. (2009) [43]. The quantification of BRs was performed using high-performance liquid chromatography-electrospray ionization-tandem mass spectrometry (HPLC-ESI-MS/MS) according to the protocol of Ding et al. (2013) [42]. The BRs were quantified using a calibration curve with known amounts of standards and based on the ratios of the summed area of the multiple reaction monitoring (MRM) transitions for BRs. Data acquisition and analysis were performed using the Xcalibur Data System (Thermo Fisher Scientific, Waltham, MA, USA). The BRs level was expressed as pmol $\mathrm{g}^{-1}$ dry weight (DW). In this study, 24epicastasterone (24-epiCS) and 28-homobrassinolide (28-homoBL) were analyzed because they are the most important BRs in rice plants due to their high biological activity [44].

\section{Determination of genes expression levels}

The expression levels of key BRs synthesis gene OsD11 [45], AsA synthesis and metabolic related genes OsMPG1 (encodes GMPase), OsDHAR1, OsMDHAR3, OsAPX1 and OsAPX2 [46-49], a key sugar metabolism gene OsCSA [33] in rice young panicles were analyzed at SPD, PMC and PF stages. The expression levels of key inflorescence development genes OsAPO2 and OsTAW1 in young panicles were determined at the SPD stage since they are mainly expressed at transition from inflorescence meristem to spikelet meristem in rice [7]. Transcript levels of the genes were measured by qRT-PCR using an iCycler (Bio-Rad, Hercules, CA, USA) with iQ SYBR Green Supermix (Bio-Rad). The gene accession numbers and gene-specific primer pairs used for qRTPCR are listed in Additional file 1: Table S1. Rice ACTIN1 was used as an internal reference for all analyses. Three replicates were performed for each sample.

\section{Determination of contents of $\mathrm{AsA}$ and $\mathrm{H}_{2} \mathrm{O}_{2}$, and activities of APX, DHAR and MDHAR}

Measurement of AsA content was performed by a HPLC system (Waters 2695 separation module, Waters Corp, Millford, MA, USA) according to the method of Wang et al. (2013) [22]. The AsA content was calculated by comparison with the values obtained from a standard curve. The $\mathrm{H}_{2} \mathrm{O}_{2}$ content in young panicles was measured using the method of Rao et al. (2000) [50]. Both AsA and $\mathrm{H}_{2} \mathrm{O}_{2}$ contents were expressed as $\mu \mathrm{mol} \mathrm{g}^{-1} \mathrm{DW}$.
The activities of APX, DHAR and MDHAR were measured using the methods of Gomez and Lajolo (2010) [51] and Hou and Lin (1997) [52], respectively. Oxidation or reduction of $1 \mu \mathrm{mol}$ AsA per gram dry weight (DW) of samples per min at $25^{\circ} \mathrm{C}$ was defined as a unit of the activity for APX or for DHAR, and oxidation of $1 \mu \mathrm{mol}$ nicotinamide adenine dinucleotide (NADH) per gram dry weight of samples per min at $25^{\circ} \mathrm{C}$ as a unit of the activity for MDHAR. Activities of the three enzymes were expressed as unit $\mathrm{g}^{-1} \mathrm{DW} \mathrm{min}^{-1}$.

\section{Construction of transgenic line (D11-RNAi, called DR-1) and soil moisture treatments}

The methods of constructing the artificial RNAi vector and transformation were as described by Zhu et al. (2015) [33]. Seeds of the WT and DR-1 were sown in the field, and thirty-day-old seedlings were then transplanted into porcelain pots $(25-\mathrm{cm}$ height, $20-\mathrm{cm}$ diameter, and 7.75-L volume for each pot) with one seedling per pot during the rice growing season. Each pot was filled with $7.0 \mathrm{~kg}$ of sandy loam soil (Typic Fluvaquent, Entisol, US classification), and the soil composition was as described above. Both the WW $\left(\Psi_{\text {soil }}=0 \mathrm{kPa}\right)$ and MD $\left(\Psi_{\text {soil }}=-10\right.$ to $\left.-15 \mathrm{kPa}\right)$ treatments were imposed from the onset of panicle initiation to the heading time. The treatment details, water management, and rain prevention were the same as those in the field experiment. Each treatment consisted of 80 pots and 100-120 young panicles were sampled at the SPD stage, 20-30 young panicles were sampled at PMC and PF stages to measure the contents of BRs (24-epiCS +28-homoBL), AsA and $\mathrm{H}_{2} \mathrm{O}_{2}$, and relative expression levels of OsD11, OsCSA, OsMPG1, OsDHAR1, OsMDHAR3, OsAPX1 and OsAPX2, and activities of APX, DHAR and MDHAR in young panicles. The expression levels of OsAPO2 and OsTAW1 in young panicles were determined at the SPD stage. At the three stages, the amount of NSC in the shoots (culm + sheath + leaf blade + panicle) was determined. The number of differentiated or degenerated spikelets in a panicle was determined from 60 panicles in each treatment at the heading stage. The methods used for the determinations were the same as those described above.

\section{Chemical application}

At the onset of SPD, $10 \mathrm{nmol} \mathrm{L}{ }^{-1}$ BRs (24-epiCS + 28homoBL) (eBRs), $2 \mathrm{mmol} \mathrm{L}^{-1}$ AsA (eAsA), or $2 \mathrm{mmol}$ $\mathrm{L}^{-1}$ AsA $+10 \mathrm{mmol} \mathrm{L}^{-1}$ sucrose [e (AsA + sucrose)] was applied to the panicles of $D R-1$ or SD treated-YD-6, and $10 \mathrm{nmol} \mathrm{L}^{-1}$ BRZ (eBRZ) or $50 \mathrm{mmol} \mathrm{L}^{-1} \mathrm{H}_{2} \mathrm{O}_{2}$ $\left(\mathrm{eH}_{2} \mathrm{O}_{2}\right)$ was applied to the panicles of WT or YD-6 in the WW treatment by carefully injecting the solution $2 \mathrm{~cm}$ from the basal stem with a 1-mL syringe (UltraFine Needle Insulin Syringe, Becton, Dickinson and 
Company). The injection site is shown in the diagram (Fig. 7a). Physical damage caused by the injection event was not observed since the pinhole was very fine $(0.33$ $\mathrm{mm})$. The chemicals were applied daily for 3 days at the onset of the SPD stage with $0.5 \mathrm{~mL}$ of solution per panicle per day. All the solutions contained ethanol at a final concentration of $0.05 \%(\mathrm{v} / \mathrm{v})$. Control plants (CK) received the same volume of deionized water containing the same concentration of ethanol. The $D R-1$ and WT plants were pot-grown as described above, and the WW treatment was imposed from the onset of panicle initiation to the heading time, with 40 replicate pots. The cultivar YD-6 was field grown as described above under the WW and SD conditions with three replications. Each chemical treatment included 80 young panicles as replicates, and these panicles were tagged.

In each chemical treatment, the expression levels of OsAPO2 and OsTAW1 in young panicles were determined at the SPD stage, contents of AsA, $\mathrm{H}_{2} \mathrm{O}_{2}$ and NSC, activities of APX, DHAR and MDHAR, expression levels of OsCSA, OsMPG1, OsDHAR1, OsMDHAR3, OsAPX1 and OsAPX2 in young panicles were determined at the PMC stage, and contents of BRs (24-epiCS + 28-homoBL) were determined at both SPD and PMC stage. The number of differentiated or degenerated spikelets in a panicle was determined at the heading stage. The methods used for the determinations were the same as those described above.

\section{Statistical analysis}

Analysis of variance was performed using the SAS/STAT statistical analysis package (version 9.2, SAS Institute, Cary, NC, USA). Data from each sampling date were analyzed separately. Means were tested by a least significant difference (LSD) test at the $P=0.05$ level $\left(\mathrm{LSD}_{0.05}\right)$.

\section{Supplementary information}

Supplementary information accompanies this paper at https://doi.org/10. 1186/s12870-019-2025-2.

\footnotetext{
Additional file 1: Table S1. List of the primers used for qRT-PCR analyses. Fig. $\mathbf{S 1}$ Changes in relative expression levels of genes in young panicles of the rice cultivar YD-6 under well-watered, moderate soildrying and severe soil-drying treatments. Fig. S2 Changes in relative expression levels of genes in young panicles of WT and DR-1 under wellwatered and moderate soil-drying treatments. Fig. S3 Changes in relative expression levels of key rice inflorescence development genes in young panicles of YD-6, ZH10 (WT) and OsD11 RNAi line (DR-1) under various soil moisture treatments. Fig. S4 Effect of exogenous brassinosteroids and brassinazole on relative expression levels of ascorbic acid synthesis and cycle, or sugar metabolism genes in young panicles of YD-6, ZH10 (WT) and OsD11 RNAi line (DR-1). Fig. S5 Effect of exogenous brassinosteroids and brassinazole on relative expression levels of key rice inflorescence development genes in young panicles of YD-6, ZH10 (WT) and OsD11 RNAi line $(D R-1)$. Fig. S6 Effect of exogenous brassinosteroids and brassinazole on physiological traits and spikelet development of rice cultivar YD-6 under well-watered and severe soil-drying treatments. Fig. S7 Effect of exogenous $\mathrm{H}_{2} \mathrm{O}_{2}$, ascorbic acid and sucrose on endogenous $\mathrm{H}_{2} \mathrm{O}_{2}$
}

content in young panicles, spikelet differentiation and degeneration of YD-6, ZH10 (WT) and OsD11 RNAi line (DR-1).

\section{Abbreviations}

24-epiCS: 24-epicastasterone; 28-homoBL: 28-homobrassinolide; AO: Ascorbic acid oxidase; AOS: Antioxidant system; APX: Ascorbic acid peroxidase; AsA: Ascorbic acid; BRS: Brassinosteroids; BRZ: Brassinazole;

DHAR: Dehydroascorbate reductase; GMPase: GDP-D-mannose

pyrophosphorylase; GSH: Glutathione; GSSH: oxidized Glutathione; LAl: Leaf area index; MD: Moderate soil-drying; MDHAR: Monodehydroascorbate reductase; NSC: Nonstructural carbohydrates; PF: Pollen filling; PMC: Pollen mother cell meiosis; ROS: Reactive oxygen species; SD: Severe soil-drying; SPD: Spikelet primordium differentiation; WW: Well-watered

\section{Acknowledgements}

Not applicable.

\section{Authors' contribution}

$J Y$ and JZ conceived and designed research. WZ, JS, YX, WW, and YW conducted experiments. WZ, ZW and FX analyzed data. The manuscript was written by WZ and JY. All authors read and approved the manuscript.

\section{Funding}

This study was financially supported by the grants from the National Natural Science Foundation of China (31461143015, 31771710), the National Key Research and Development Program of China (2016YFD0300206-4, 2018YFD0300801), the Priority Academic Program Development of Jiangsu Higher Education Institutions (PAPD), the Top Talent Supporting Program of Yangzhou University (2015-01), the Council of Hong Kong Baptist University (1806439), the Project funded by China Postdoctoral Science Foundation (2018 M640528), and the Open Project from Joint International Research Laboratory of Agriculture and Agri-Product Safety of Yangzhou University (JRK2018004). These funding bodies did not play any roles in the design of the study and collection, analysis, and interpretation of data and in writing the manuscript.

\section{Availability of data and materials}

All relevant data are within this article and its Additional files.

\section{Ethics approval and consent to participate}

Not applicable.

\section{Consent for publication \\ Not applicable.}

\section{Competing interests}

The authors declare that they have no competing interests.

\section{Author details}

${ }^{1}$ Jiangsu Key Laboratory of Crop Genetics and Physiology/Jiangsu Key Laboratory of Crop Cultivation and Physiology, Agricultural College of Yangzhou University, Yangzhou 225009, China. 'Jiangsu Co-Innovation Center for Modern Production Technology of Grain Crops, Yangzhou University, Yangzhou 225009, China. ${ }^{3}$ Joint International Research Laboratory of Agriculture and Agri-Product Safety, the Ministry of Education of China, Yangzhou University, Yangzhou 225009, Jiangsu, China. ${ }^{4}$ College of Bioscience and Biotechnology, Yangzhou University, Yangzhou 225009, Jiangsu, China. ${ }^{5}$ Department of Biology, Hong Kong Baptist University, Hong Kong, China.

Received: 17 May 2019 Accepted: 10 September 2019

Published online: 18 September 2019

\section{References}

1. Tang CJ, Sun YJ, Xu HS, Yu SB. Identification of quantitative trait locus and epistatic interaction for degenerated spikelets on the top of panicle in rice. Plant Breed. 2011;130(2):177-84.

2. $\quad$ Ding CQ, You J, Chen L, Wang SH, Ding YF. Nitrogen fertilizer increases spikelet number per panicle by enhancing cytokinin synthesis in rice. Plant Cell Rep. 2014;33(2):363-71. 
3. Zhang WY, Zhu KY, Wang ZQ, Zhang H, Gu JF, Liu LJ, et al. Brassinosteroids function in spikelet differentiation and degeneration in rice. J Integr Plant Biol. 2019;61(8):943-63.

4. Ashikari M, Sakakibara H, Lin S, Yamamoto T, Takashi T, Nishimura A, et al. Cytokinin oxidase regulates rice grain production. Science. 2005;309(5735): 741-5.

5. Wang ZQ, Zhang WY, Yang JC. Physiological mechanism underlying spikelet degeneration in rice. J Integr Agr. 2018;17(7):60345-7.

6. Liao C, Peng Y, Ma W, Liu R, Li C, Li X. Proteomic analysis revealed nitrogenmediated metabolic, developmental, and hormonal regulation of maize (Zea mays L.) ear growth. J Exp Bot. 2012;63(14):5275-88.

7. Zhang D, Yuan Z. Molecular control of grass inflorescence development. Annu Rev Plant Biol. 2014;65(2014):553-78.

8. Ding CQ, Wang Y, Chang ZY, You SL, Liu ZH, Wang SH, Ding YF. Comparative proteomic analysis reveals nitrogen fertilizer increases spikelet number per panicle in rice by repressing protein degradation and 14-3-3 proteins. J Plant Growth Regul. 2016;35(3):744-54.

9. Ding CQ, Wang Y, You SL, Liu ZH, Wang SH, Ding YF. Digital gene expression analysis reveals nitrogen fertilizer increases panicle size by repressing Hd3a signaling in rice. Plant Growth Regul. 2016;79(1):47-54.

10. Zhang WY, Chen YJ, Wang ZQ, Yang JC. Polyamines and ethylene in rice young panicles in response to soil drought during panicle differentiation. Plant Growth Regul. 2017;82:491-503.

11. Saini HS, Westgate ME. Reproductive development in grain crops during drought. Adv Agron. 2000;68(1):59-96.

12. Yang JC, Zhang JH, Liu K, Wang ZQ, Liu LJ. Abscisic acid and ethylene interact in rice spikelets in response to water stress during meiosis. J Plant Growth Regul. 2007;26(4):318-28.

13. Yang JC, Zhang JH, Wang ZQ, Zhu QS, Wang W. Hormonal changes in the grains of rice subjected to water stress during grain filling. Plant Physiol. 2001;127(1):315-23.

14. Yang JC, Zhang JH, Wang ZQ, Xu GW, Zhu QS. Activities of key enzymes in sucrose-to-starch conversion in wheat grains subjected to water deficit during grain filling. Plant Physiol. 2004;135(3):1621-9.

15. Yang JC, Zhang JH. Crop management techniques to enhance harvest index in rice. J Exp Bot. 2010;61(12):3177-89.

16. Ye HX, Liu SZ, Tang BY, Chen JN, Xie ZL, Nolan TM, et al. RD26 mediates crosstalk between drought and brassinosteroid signalling pathways. Nat Commun. 2017;8:14573.

17. Lv BS, Tian HY, Zhang F, Liu JJ, Lu SH, Bai MY, et al. Brassinosteroids regulate root growth by controlling reactive oxygen species homeostasis and dual effect on ethylene synthesis in Arabidopsis. PLoS Genet. 2018;14(1): e1007144.

18. Ahmad P, Jaleel AC, Salem AM, Nabi G, Sharma S. Roles of enzymatic and nonenzymatic antioxidants in plants during abiotic stress. Crit Rev Biotechnol. 2010;30(3):161-75.

19. Mittler R, Vanderauwera S, Suzuki N, Miller G, Tognetti VB, Vandepoele K, et al. ROS signaling: the new wave? Trends Plant Sci. 2011;16(6):300-9

20. Heng YQ, Wu CY, Long Y, Luo S, Ma J, Chen J. OsALMT7 maintains panicle size and grain yield in rice by mediating malate transport. Plant Cell. 2018; 30:889-906.

21. Chen TT, Xu YJ, Wang JC, Wang ZQ, Yang JC, Zhang JH. Polyamines and ethylene interact in rice grains in response to soil drying during grain filling. J Exp Bot. 2013;64(8):2523-38.

22. Wang J, Yu Y, Zhang Z, Quan R, Zhang H, Ma L, et al. Arabidopsis CSN5B interacts with VTC1 and modulates ascorbic acid synthesis. Plant Cell. 2013; 25:625-36.

23. Megha S, Basu U, Kav NNV. Regulation of low temperature stress in plants by microRNAs. Plant Cell Environ. 2018;41(1):1-15.

24. Zhang ZJ, Chu G, Liu LJ, Wang ZQ, Wang XM, Zhang H, et al. Mid-season nitrogen application strategies for rice varieties differing in panicle size. Field Crop Res. 2013;150:9-18.

25. Tanabe S, Ashikari M, Fujioka S, Takatsuto S, Yoshida S, Yano M, et al. A novel cytochrome P450 is implicated in brassinosteroid biosynthesis via the characterization of a rice dwarf mutant, dwarf11, with reduced seed length. Plant Cell. 2005;17(3):776-90.

26. $\mathrm{Li} H$, Jiang L, Youn $\mathrm{JH}$, Sun $W$, Cheng $Z J$, Jin TY. A comprehensive genetic study reveals a crucial role of CYP90D2/D2 in regulating plant architecture in rice (Oryza sativa). New Phytol. 2013;200(4):1076-88.

27. Liu JM, Park SJ, Huang J, Lee EJ, Xuan YHJBI, Kumar V, et al. Loose plant Architecture1 (LPA1) determines lamina joint bending by suppressing auxin signalling that interacts with C-22-hydroxylated and 6-deoxo brassinosteroids in rice. J Exp Bot. 2016;67(6):1883-95.

28. Tian YC, Fan M, Qin ZX, Lv HJ, Wang MM, Zhang Z, et al. Hydrogen peroxide positively regulates brassinosteroid signaling through oxidation of the BRASSINAZOLE-RESISTANT1 transcription factor. Nat Commun. 2018;9(1): 1063.

29. Fang N, Xu R, Huang LJ, Zhang BL, Duan PJ, Li N, et al. SMALL GRAIN 11 controls grain size, grain number and grain yield in rice. Rice. 2016;9(1):64

30. Wu YZ, Fu YC, Zhao SS, GU P, Zhu ZF, Sun CQ, et al. CLUSTERED PRIMARY BRANCH 1, a new allele of DWARF11, controls panicle architecture and seed size in rice. Plant Biotechnol J. 2016;14(1):377-86.

31. Zhang CX, Feng BH, Chen TT, Zhang XF, Tao LX, Fu GF. Sugars, antioxidant enzymes and IAA mediate salicylic acid to prevent rice spikelet degeneration caused by heat stress. Plant Growth Regul. 2017;83(2):313-23.

32. Zhang $H$, Liang $W$, Yang $X$, Luo $X$, Jiang N, Ma H, et al. Carbon starved anther encodes a MYB domain protein that regulates sugar partitioning required for rice pollen development. Plant Cell. 2010;22(3):672-89.

33. Zhu XL, Liang WQ, Cui X, Chen MJ, Yin CS, Luo ZJ, et al. Brassinosteroids promote development of rice pollen grains and seeds by triggering expression of carbon starved anther, a MYB domain protein. Plant J. 2015; 82:570-81.

34. Wu WL, Zhang Q, Ervin EH, Yang ZP, Zhang XZ. Physiological mechanism of enhancing salt stress tolerance of perennial ryegrass by 24-Epibrassinolide. Front Plant Sci. 2017;8:1017.

35. Koffler BE, Luschin-Ebengreuth N, Stabentheiner E, Müller M, Zechmann B. Compartment specific response of antioxidants to drought stress in arabidopsis. Plant Sci. 2014;227:133-44.

36. Kumar R, Mustafiz A, Sahoo KK, Sharma V, Samanta S, Sopory SK, et al. (2012). Functional screening of cdna library from a salt tolerant rice genotype pokkali identifies mannose-1-phosphate guanyl transferase gene (OSMPG1) as a key member of salinity stress response. Plant Mol. Biol. 2012; 79(6):555-568.

37. Agrawal GK, Jwa NS, Iwahashi H, Rakwal R. Importance of ascorbate peroxidases OSAPX1 and OSAPX2 in the rice pathogen response pathways and growth and reproduction revealed by their transcriptional profiling. Gene. 2003:322:93-103.

38. Navrot N, Rouhier N, Gelhaye E, Jacquot JP. Reactive oxygen species generation and antioxidant systems in plant mitochondria. Physiol Plantarum. 2007;129(1):185-95.

39. Ling QH, Su ZF, Chang HC, Cai JZ, Ho JS. The leaf-age model of development process in different varieties of rice. Sci Agric Sin. 1983;16:9-18.

40. Wang ZQ, Zhang WY, Beebout SS, Zhang H, Liu L, Yang JC, et al. Grain yield, water and nitrogen use efficiencies of rice as influenced by irrigation regimes and their interaction with nitrogen rates. Field Crop Res. 2016;193:54-69.

41. Yoshida S, Forno D, Cock J, Gomez KA. Laboratory manual for physiological studies of Rice: International Rice Research Institute, the Philippines; 1976.

42. Ding J, Mao $\sqcup$, Yuan BF, Feng YQ. A selective pretreatment method for determination of endogenous active brassinosteroids in plant tissues: double layered solid phase extraction combined with boronate affinity polymer monolith microextraction. Plant Methods. 2013;9:13.

43. Chen M, Lu Y, Ma Q, Guo L, Feng YQ. Boronate affinity monolith for highly selective enrichment of glycopeptides and glycoproteins. Analyst. 2009; 134(10):2158-64.

44. Bajguz A, Tretyn A. The chemical characteristic and distribution of brassinosteroids in plants. Phytochemistry. 2003;62(7):1027-46.

45. Zhang C, Bai MY, Chong K. Brassinosteroid-mediated regulation of agronomic traits in rice. Plant Cell Rep. 2014;33:683-96.

46. Kim YS, Kim IS, Bae MJ, Choe YH, Kim YH, Park HM. Homologous expression of cytosolic dehydroascorbate reductase increases grain yield and biomass under paddy field conditions in transgenic rice (Oryza sativa L. japonica). Planta. 2013;237(6):1613-25.

47. Li ZW, Su D, Lei BT, Wang FB, Geng W, Pan G, et al. Transcriptional profile of genes involved in ascorbate glutathione cycle in senescing leaves for an early senescence leaf (es/) rice mutant. J Plant Physiol. 2015;176:1-15.

48. Qin H, Deng ZJ, Zhang CY, Wang YY, Wang J, Liu H, et al. Rice GDPmannose pyrophosphorylase OsVTC1-1 and OsVTC1-3 play different roles in ascorbic acid synthesis. Plant Mol Biol. 2016;90(3):317-27.

49. Kim JJ, Kim YS, Park SI, Mok JE, Kim YH, Park HM. Yoon cytosolic monodehydroascorbate reductase gene affects stress adaptation and grain yield under paddy field conditions in Oryza sativa L. japonica. Mol Breeding. 2017;37(10):118 
50. Rao M, Lee H, Creelman RA, Mullet JE, Davis KR. Jasmonic acid signaling modulates ozone-induced hypersensitive cell death. Plant Cell. 2000;12(9): 1633-46.

51. Gomez MLP, Lajolo FM. Ascorbic acid metabolism in fruits: activity of enzymes involved in synthesis and degradation during ripening in mango and guava. J Sci Food Agr. 2010;88(8):756-62.

52. Hou WC, Lin YH. Dehydroascorbate reductase and monodehydroascorbate reductase activities of trypsin inhibitors, the major sweet potato (Ipomoea batatas L. lam) root storage protein. Plant Sci. 1997;128(2):151-8.

\section{Publisher's Note}

Springer Nature remains neutral with regard to jurisdictional claims in published maps and institutional affiliations.

Ready to submit your research? Choose BMC and benefit from:

- fast, convenient online submission

- thorough peer review by experienced researchers in your field

- rapid publication on acceptance

- support for research data, including large and complex data types

- gold Open Access which fosters wider collaboration and increased citations

- maximum visibility for your research: over $100 \mathrm{M}$ website views per year

At $B M C$, research is always in progress.

Learn more biomedcentral.com/submissions 